\title{
Cytomorphological Spectrum of Salivary Gland Lesions by Fine Needle Aspiration Cytology
}

\author{
Mayur Ambekar', Rachana Binayke ${ }^{2}$ \\ ${ }^{1}$ MD Pathology, Ex Resident Pathologist, ${ }^{2}$ MD Pathology, Associate Professor, \\ Grant Government Medical College and Sir J J Group of Hospitals, Mumbai \\ Corresponding Author: Rachana Binayke
}

\begin{abstract}
Introduction: Salivary gland lesions encompass a baffling subset of lesions with overlapping morphologies on cytomorphology, due to their heterogenous histologies and rare enough to sometimes bewilder even the most knowledgeable cytopathologists. The technique of fine needle aspiration (FNA) cytology in the evaluation of salivary gland lesion is simple to perform, saves time, reliable, safe and inexpensive. FNA is highly accurate when used in proper clinical setting and supported by appropriate clinical and relevant diagnostic data. Rapidity of obtaining a pathological diagnosis allows more intelligent therapeutic approach.
\end{abstract}

Materials and Methods: It was a prospective study carried out in the cytology section of pathology department for a period of two years using fine needle aspiration as a diagnostic tool as per standard protocol. The clinical and radiological data were obtained from the patient's case papers and collaboration with the operating surgeon, the lesions were analysed on cytology. Haematoxylin \& Eosin, Papanicolaou stain and Giemsa were used as standard stains.

Results: A total of 66 cases of salivary gland lesions were aspirated for a period of two years. Majority of cases were in the age group of 21-30 years with 36 male patients $(55 \%)$ and 30 female patients (45\%). About 44(66.7\%), $19(28.8 \%), 1(1.5 \%)$ and 2(3.0\%) cases occurred in parotid gland, submandibular gland, sublingual gland and minor salivary gland respectively. There were $21(32 \%)$ cases of nonneoplastic lesions and 45(68\%) cases of neoplastic lesions. Histopathological specimens were available in 11 out of 66 cases and showed correlation with cytological findings.
Conclusion: Fine needle aspiration cytology of salivary gland lesions has high diagnostic accuracy, helps in appropriate therapeutic management and is useful as a diagnostic procedure because of the availability of earlier diagnosis in comparison with the histopathology.

Key Words: Salivary gland lesions, fine needle aspiration cytology, neoplastic, non-neoplastic

\section{INTRODUCTION}

Salivary gland tissue is distributed widely and consists of paired major salivary glands - the Parotid, the Submandibular and the Sublingual glands as well as minor salivary glands which occur in scattered locations, along the upper aerodigestive tract ${ }^{[1,2]}$. The major and minor salivary glands are subjected to developmental, inflammatory, immunopathic, degenerative and neoplastic diseases. Salivary gland tumours are infrequent in surgical pathology and encompass a mere $3.5-5 \%$ of all head and neck lesions; however tend to pose a challenging diagnostic problem due to such an extensive differential diagnosis ${ }^{[1]}$.

Fine needle aspiration (FNA) is a useful adjunct for presumptively or, in many instances, definitively diagnosing salivary gland neoplasms. The important aspect of this technique is to avoid the surgeries in situations like inflammatory lesions and also help in rationally planning of surgery. FNA is an effective modality for salivary gland lesion evaluation, providing rapid and valuable initial triage information, such as 
salivary versus non-salivary origin, benign versus malignant, low-grade versus high$\operatorname{grade}^{[3]}$.

\section{MATERIALS AND METHODS}

The following study was a two-year hospital-based study on the cytomorphological spectrum of salivary gland lesions using fine needle aspiration as a mode of diagnostic test, referred to the cytology section of Department of Pathology at a tertiary care hospital. Patient's relevant details of clinical history, physical examination was obtained in each case. Patient was explained about the procedure and informed consent taken. A 22-24-gauge needle was used for the procedure. A minimum of three slides prepared, one air dried slide stained by May Grunwald-Giemsa (MGG) and other two slides fixed in alcohol stained with Haematoxylin \& Eosin (H \& E) and Papanicolaou stain (PAP). FNA were further correlated with histopathological diagnosis from paraffin embedded sections of tissue blocks, fixed in $10 \%$ formalin whenever available.

\section{RESULTS}

This two-year prospective study comprised of 66 cases of salivary gland swellings in which 36 were male and 30 were female patients. The maximum incidence of salivary gland lesions, were seen between the ages of 21-30 years, followed by 41-50 years (Fig 1). The commonest gland involved was the parotid gland in both the sexes. Out of 66 cases studied, swelling was the commonest mode of presentation $(100 \%)$ followed by fixity $(51.5 \%)$ and pain $(25.8 \%)$. In the present study, 44(66.7\%), 19(28.8\%), 1(1.5\%) and $2(3.0 \%)$ cases occurred in parotid gland, submandibular gland, sublingual gland and minor salivary gland respectively (Fig 2). There were $21(32 \%)$ cases of non-neoplastic lesions and $45(68 \%)$ cases of neoplastic lesions. Out of the neoplastic lesions, 42 (93\%) cases were benign tumors and $3(7 \%)$ cases were malignant tumors. Benign tumors were common in the younger age group (21-30 years) and malignant tumors were common in the older age groups (4170 years). Of the 21 cases of non-neoplastic salivary gland lesions, sialadenitis constituted $17(81 \%)$ cases, sialadenosis constituted 3(14.3\%) while mucocele constituted $1(4.7 \%)$ case. Pleomorphic adenoma was the most common benign salivary gland tumour accounting for $73.4 \%$ of all tumors. Mucoepidermoid carcinoma was the most common malignant salivary gland tumour accounting for $4.4 \%$ of all tumours (Fig 3). Histopathological correlation was available for 11 out of 66 cases, and correlated with the cytological diagnosis.

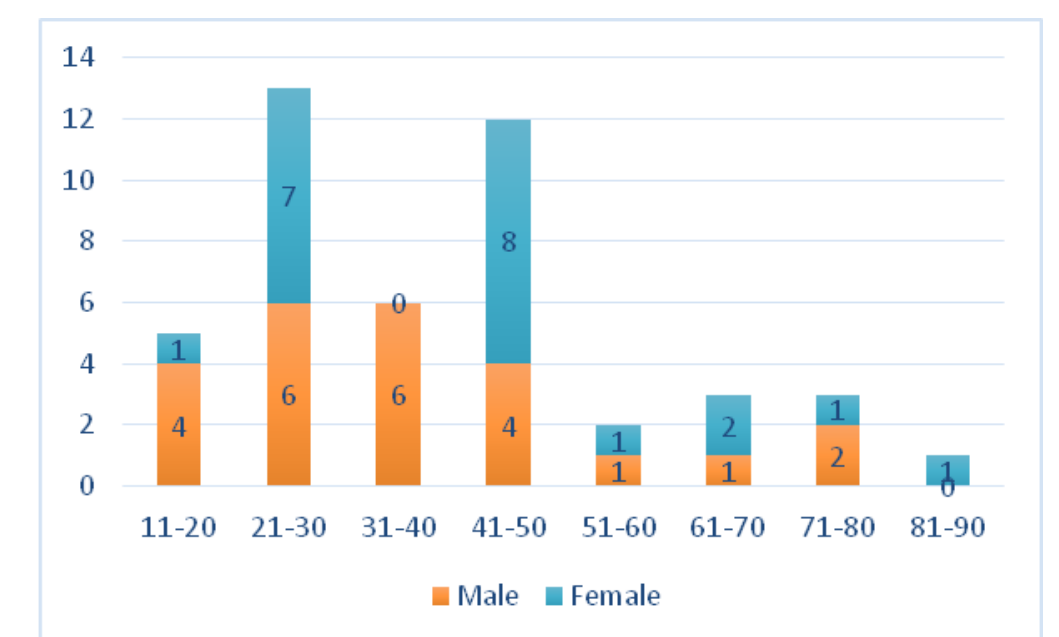

Figure 1: Enumeration of salivary gland lesions showing gender and age wise distribution. 


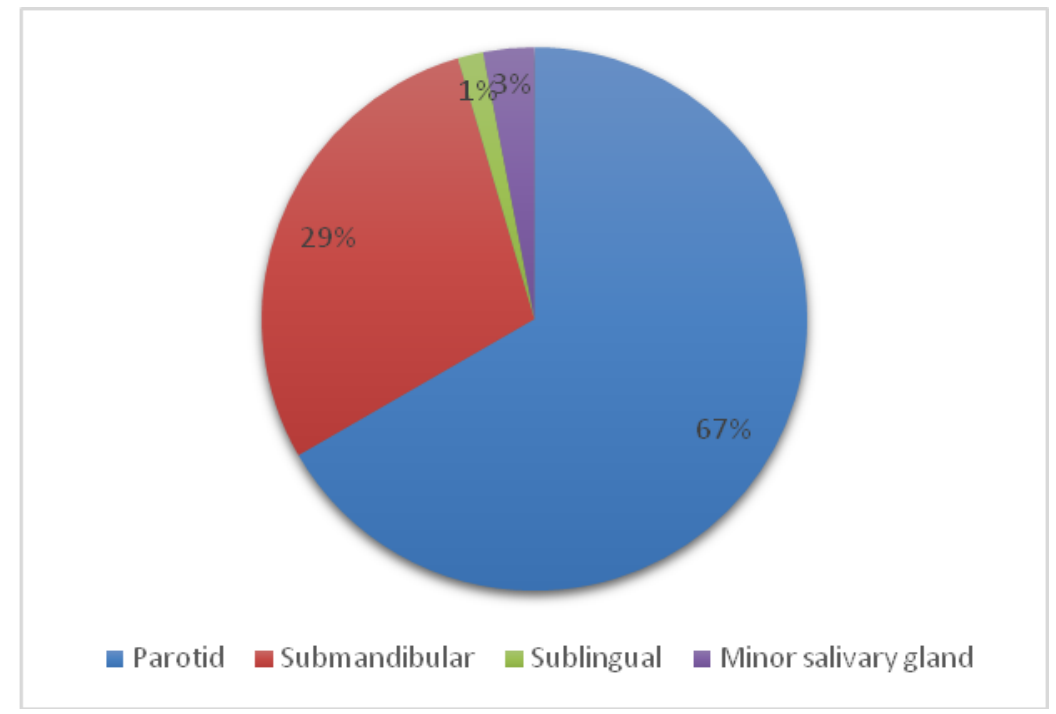

Figure 2: Distribution of salivary gland lesions according to anatomical location.

Figure 3: Distribution of salivary gland tumors and their incidence
\begin{tabular}{|l|l|l|l|}
\hline Sr no & FNAC diagnosis & No of cases & Percentage $(\%)$ \\
\hline 1 & Pleomorphic adenoma & 33 & 73.4 \\
\hline 2 & Warthin's tumor & 5 & 11.2 \\
\hline 3 & Monomorphic adenoma & 2 & 4.4 \\
\hline 4 & Basal cell adenoma & 1 & 2.2 \\
\hline 5 & Oncocytoma & 1 & 2.2 \\
\hline 6 & Mucoepidermoid & 2 & 4.4 \\
\hline 7 & Acinic cell carcinoma & 1 & 2.2 \\
\hline & Total & 45 & 100 \\
\hline
\end{tabular}

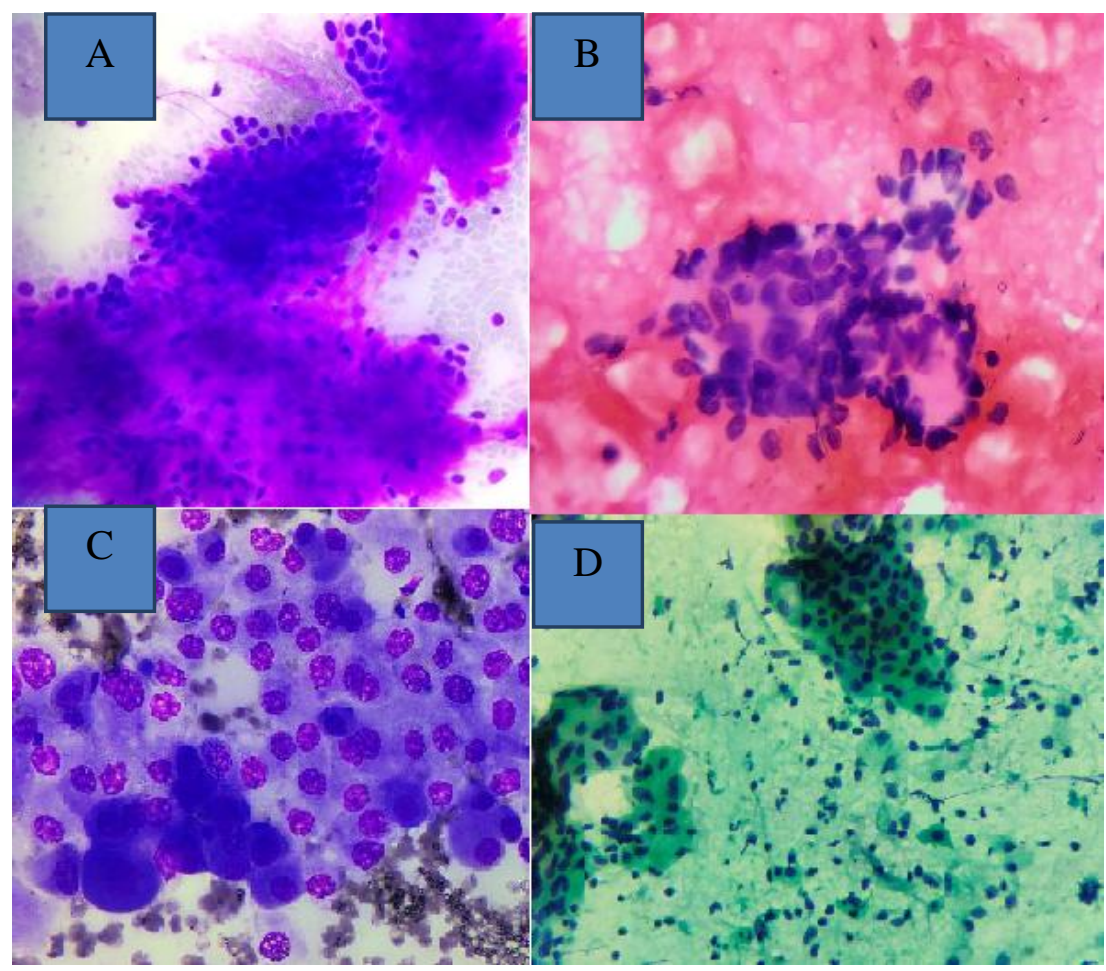

Fig 4:

A: Microphotograph of pleomorphic adenoma showing epithelial cells, myoepithelial cells with abundant fibro myxoid stroma. (MGG, 400X).

B: Microphotograph of basal cell adenoma showing multiple small rounded hyaline stromal nodules surrounded by small bland epithelial cells. (H\&E, 400X).

C: Microphotograph of acinic cell carcinoma showing relatively uniform, cohesive cells with abundant cytoplasm and round nucleus with bland chromatin. (MGG, 400X).

D: Microphotograph of low grade mucoepidermoid carcinoma showing epithelial fragment of intermediate cells, squamoid cells and occasional cell with intracytoplasmic mucin. (PAP, 400X) 


\section{DISCUSSION}

The two-year prospective study aimed to classify salivary gland tumours according to WHO Head and Neck [4] terminology and Milan system of Cytopathological reporting ${ }^{[5]}$ to avoid unwarranted surgeries. Even though the present WHO classification aims at diagnosis aided by molecular classification, cytomorphology and histomorphology still stands as the cornerstone of its diagnosis. In this study, $64-80 \%$ of all primary epithelial tumors occurred in the parotid glands, 7$11 \%$ occurred in the submandibular glands, $<1 \%$ occurred in the sublingual glands and 9-23\% occur in the minor salivary glands. $15-30 \%$ of the tumors in the parotid glands were malignant in contrast to $40 \%$ in the submandibular gland, 50\% in minor salivary gland and $70-90 \%$ in sublingual glands. These findings were in concordance to Roland $\mathrm{NJ}$ et al ${ }^{[6]}$ and Boccato $\mathrm{P}$ et al ${ }^{[7]}$, however in the studies conducted by Das DK et al ${ }^{[8]}$ and Omhare et al ${ }^{[9]}$ we saw an increased incidence of submandibular gland tumours. These findings also conclude the general understandings that in the minor salivary glands, as many as $50 \%$ of tumors are malignant, most often located in the palate [10]. In this study the male to female ratio was 1.2:1 which were similar with the studies conducted by Das DK et al ${ }^{[8]}$ and Omhare et al ${ }^{[9]}$. Pleomorphic adenoma and mucoepidermoid carcinoma were the most common benign and malignant tumors respectively. The rate of occurrence of pleomorphic adenoma was similar to the studies of Stewart CJR et al ${ }^{[11]}$ and Jesus Souza et al ${ }^{[12]}$. The most common malignant tumor was mucoepidermoid carcinoma in the present study which is similar to the other studies conducted by Jesus Souza et al ${ }^{[12]}$ and Omhare et al ${ }^{[9]}$. In a study conducted by Stewart CJ et al ${ }^{[11]}$, adenocarcinoma was the primary malignant salivary gland tumor. FNA's sensitivity and specificity in differentiating between benign and malignant lesions are $80 \%$ and $97 \%$, respectively. ${ }^{[13]}$ However, FNA might not always help in understanding tumor subtypes.
In the present study, the diagnostic accuracy was $100 \%$, possibly due to the smaller sample size and a good clinico-pathological correlation. In comparison to other studies, similar results of a good cytohistomorphological correlation were seen namely in Cristallini EG et al ${ }^{[14]}$, Shintani et al ${ }^{[15]}$ and Omhare et al ${ }^{[9]}$ where they showed 97.90\%, 93\% and $95.3 \%$ respectively. However, studies like O'Dwyer et al ${ }^{[16]}$ and Jayaram et al ${ }^{[17]}$ showed a lower percentage of correlation, possibly due to the fact these were older studies and we now have a better understanding of these tumours and their cytomorphological subtypes in the recent times.

\section{CONCLUSION}

Fine needle aspiration cytology proves to have a high diagnostic accuracy and helps in appropriate therapeutic management in salivary gland lesions.

\section{ACKNOWLEDGEMENT}

The Head of Pathology Department and the Dean, Grant Government Medical College and Sir JJ Group of Hospitals, Mumbai

\section{Funding: None}

Competing Interest: None Declared

\section{Ethical Approval: Approved}

\section{REFERENCES}

1. Khandekar MM, Kavatkar AN, Patankar SA, Bagwan IB, Puranik SC, Deshmukh SD. FNAC of salivary gland lesions with histopathological correlation. Indian $\mathbf{J}$ Otolaryngol Head Neck Surg.2006; 58: 2468

2. Ten Cate's Oral Histology - 8th Edition [Internet]. Elsevier.com. 2021 [cited 17 July 2021]. Available from: https://www.elsevier.com/books/ten-catesoral-histology/nanci/978-0-323-07846-7

3. Sun J. Yang X. A Review of Cytology of Salivary Gland Lesions: Old, Updated and New. NA J Med Sci. 2015;8(1):31-37. 
4. Who classification of head and neck tumours. 4th ed. Lyon: International agency for research on cancer; 2017: 159-201

5. Faquin W, Rossi E, Baloch Z, Barkan G, Foschini M, Kurtycz D et al. The Milan System for Reporting Salivary Gland Cytopathology.

6. Roland NJ, Caslin AW, Smith PA, Turnbull LS, Panarese A, Jones Fine needle aspiration cytology of salivary gland lesions reported immediately in a head and neck clinic. J Laryngol Otol.1993;107(11):1025-8

7. Boccato P. Altavilla G, Blandamura S. Fine needle aspiration biopsy of salivary gland lesions. A reappraisal of pitfalls and problems. Acta Cytol 1998 Jul-Aug;42(4): 888-98.

8. Das DK, Petkar MA, Al-Mane NM, Sheik ZA, Mallik MK, Anim JT. Role of fine needle aspiration cytology in the diagnosis of swellings in the salivary gland regions: a study of 712 cases. Med Princ Pract 2004 Mar Apr;13(2):95-106

9. Omhare A, Singh SK, Nigam JS, Sharma A. Cytohistopathological study of salivary gland lesions in Bundelkhand region, Uttar Pradesh, India. Pathology research international. 2014.

10. Carlson E, McCoy J. Margins for Benign Salivary Gland Neoplasms of the Head and Neck. Oral and Maxillofacial Surgery Clinics of North America. 2017;29(3):325340.

11. Stewart CJR, Mackenzie K, McGarry GW, Mowat A. Fine-needle aspiration cytology of salivary gland: a review of 341 cases. Diagn Cytopathol 2000;22(3):139-46.

12. Jesus Sousa, Oswald De SA. Salivary gland tumors - An analysis of 62 cases. Indian Journal of Cancer 2001; 38:38-45.

13. Schmidt R, Hall B, Wilson A, Layfield L. A Systematic Review and Meta-Analysis of the Diagnostic Accuracy of Fine-Needle Aspiration Cytology for Parotid Gland Lesions. American Journal of Clinical Pathology. 2011;136(1):45-59.

14. Cristallini EG, Ascani S, Farabi R, et al. Fine needle aspiration biopsy of salivary gland. 1985-1995. Acta Cytol 1997 SepOct;41(5):1421-5.

15. Shintani S, Matsura H, Hasegawa. Fine needle aspiration of salivary gland tumors. Int J Oral Maxillofac Surg. Aug 1997;26(4):284-6.

16. O'Dwyer P, Farr WB, James AG. Needle aspiration of major salivary glands. Its value. Cancer 1986; 57:554-7

17. Jayaram N, Ashim D, Rajnanshi A, Radhika $\mathrm{S}$, Banerjee CK. The value of salivary gland Fine needle aspiration biopsy in cytodiagnosis lesions. Diagn Cytopathol 1989; 5:349-54.

How to cite this article: Ambekar M, Binayke R. Cytomorphological spectrum of salivary gland lesions by fine needle aspiration cytology. International Journal of Research and Review. 2021; 8(7): 397-401. DOI: https://doi.org/10. 52403/ijrr.20210757 